\title{
How Can We Differentiate Malignant Biliary Strictures from Clinically Indeterminate Biliary Strictures?
}

\author{
Eui Joo Kim and Jae Hee Cho \\ Division of Gastroenterology, Department of Internal Medicine, Gil Medical Center, Gachon University College of Medicine, Incheon, Korea
}

See "Factors Associated with Malignant Biliary Strictures in Patients with Atypical or Suspicious Cells on Brush Cytology" by Ji Young Park, Tae Joo Jeon, on page 168-174.

Determining the benign or malignant nature of biliary strictures is a clinical challenge. Currently, laboratory methods, including serum tumor markers, radiological imaging studies, and pathological tissue acquisition, are the mainstay for the diagnosis of malignant biliary strictures. In an original article, Park et al. reported clinically useful parameters for the diagnosis of malignant strictures in patients with indeterminate results from imaging studies and brush cytology. The proposed clinical laboratory parameters described in the article may help clinicians differentiate malignant biliary strictures from benign strictures with indefinite findings on brush cytology. Particularly, providing effective cutoff values for variables, such as tumor markers, alkaline phosphatase, gamma-glutamyl transpeptidase, and length of stricture favoring malignancy would be highly informative to clinicians.

However, a few points of this study need deliberation. In this study, a stricture was considered as benign if no mass development was observed during a follow-up period of at least 2 years. A clinical study based on prospectively collected database data showed that malignant lesions were commonly de-

Received: January 17, 2019 Revised: January 21, 2019

Accepted: January 22, 2019

Correspondence: Jae Hee Cho

Division of Gastroenterology, Department of Internal Medicine, Gil Medical Center, Gachon University College of Medicine, 21 Namdong-daero, 774 Beongil, Namdong-gu, Incheon 21565, Korea

Tel: +82-32-460-3778, Fax: +82-32-460-3408, E-mail: jhcho9328@gmail.com ORCID: https://orcid.org/0000-0003-4174-0091

(cc) This is an Open Access article distributed under the terms of the Creative Commons Attribution Non-Commercial License (http://creativecommons.org/ licenses/by-nc/3.0) which permits unrestricted non-commercial use, distribution, and reproduction in any medium, provided the original work is properly cited. tected during the first 6 months of follow-up. ${ }^{2}$ As the duration between the initial detection of the stricture and the final diagnosis has not been presented in this study, some patients in the malignant group might have had premalignant lesions at the time of initial brush cytology with indeterminate results. It would have been better to present the duration between the initial cytology and the final diagnosis.

Moreover, in this article, brush cytology was used for pathological diagnosis. As histological diagnosis is essential for malignancies, other tissue acquisition methods or repeat cytology can be a better choice than relying on biochemical changes or imaging findings. Conventional endoscopic retrograde cholangiography (ERC)-guided biopsy or endoscopic ultrasonography-guided fine-needle aspiration (EUS-FNA) can be good alternative methods for tissue acquisition, with an excellent specificity of $>90 \% .{ }^{3,4}$ As the authors have mentioned, there are concerns about tumor seeding during EUS-FNA. However, even if a patient with a biliary stricture is a candidate for curative resection, the puncture site can be included in the en bloc resection field, and the risk of tumor seeding is considered minimal. ${ }^{5}$ If EUS-FNA is risky owing to anatomical variation, bleeding risk, or indefinite target mass lesion, other options are still available, such as ERC-guided biopsy, peroral cholangioscopy-guided endoscopic biopsy, and repeat brush cytology. $^{6-8}$ The synergistic efficacy of a combination of these tissue acquisition modalities needs to be validated in further studies.

In summary, laboratory findings, including tumor markers and stricture length on imaging studies, may be useful in the diagnosis of malignant biliary strictures with atypical or sus- 
picious cells on brush cytology. However, for more accurate diagnosis of indeterminate biliary strictures, the efficacy of other tissue acquisition modalities, including ERC, EUS, or endoscopy-guided approach, needs to be validated in further studies.

Conflicts of Interest

The authors have no financial conflicts of interest.

\section{REFERENCES}

1. Park JY, Jeon TJ. Factors associated with malignant biliary strictures in patients with atypical or suspicious cells on brush cytology. Clin Endosc 2019;52:168-174

2. Navaneethan U, Singh T, Gutierrez NG, et al. Predictors for detection of cancer in patients with indeterminate biliary stricture and atypical cells on endoscopic retrograde brush cytology. J Dig Dis 2014;15:268-275.

3. Navaneethan U, Njei B, Lourdusamy V, Konjeti R, Vargo JJ, Parsi MA. Comparative effectiveness of biliary brush cytology and intraductal biopsy for detection of malignant biliary strictures: a systematic review and meta-analysis. Gastrointest Endosc 2015;81:168-176.

4. Sadeghi A, Mohamadnejad M, Islami F, et al. Diagnostic yield of EUS-guided FNA for malignant biliary stricture: a systematic review and meta-analysis. Gastrointest Endosc 2016;83:290-298.el.

5. El Chafic AH, Dewitt J, Leblanc JK, et al. Impact of preoperative endoscopic ultrasound-guided fine needle aspiration on postoperative recurrence and survival in cholangiocarcinoma patients. Endoscopy 2013;45:883-889

6. Navaneethan U, Hasan MK, Lourdusamy V, Njei B, Varadarajulu S, Hawes RH. Single-operator cholangioscopy and targeted biopsies in the diagnosis of indeterminate biliary strictures: a systematic review. Gastrointest Endosc 2015;82:608-614.e2.

7. Kwon CI, Kim TH, Kim KA. Guide-wire assisted endobiliary forceps biopsy sampling. Clin Endosc 2017;50:404-405.

8. Amog-Jones GF, Chandra S, Jensen C, Johlin FC. Including the sheath rinse to improve cellular yield in biliary brushing cytology. Clin Endosc 2017;50:614-616. 